\title{
Tattoo Pigment Reactions-Think before You Ink
}

\author{
Sugareddy $^{1}$, Gore Vishal ${ }^{2}$ \\ ${ }^{1}$ Professor, JJM Medical College, Davanagere, Karnataka
}

${ }^{2}$ Post Graduate, Department of Dermatology, Venereology and Leprology, JJM Medical College, Davanagere, Karnataka

\begin{abstract}
Tattooing has been practiced since ancient times.Nowadays, it is very popular among young generation. With this changing trend we are witnessing increasing number of cases with complications following tattooing.These tattoo reactions may be attributed to various contents such as metallic salt in tattoo pigment, organic dyes mixed to get various colour shades or its carrier solution. Spectrum of reaction to tattoo pigments ranges from mild nonspecific inflammation to severe reactions causing significant morbidity. In our study we found lichenoid reaction is most common tattoo reactions and red dye in the tattoo pigment has been documented to elicit more reactions.
\end{abstract}

Keywords: Complications, lichenoid reaction, red dye, tattoo pigments

\section{Introduction}

Tattooing has been practiced since ancient times. It has tremendous social and religious impact. Nowadays, it is very popular among young generation. With this changing trend we are witnessing increasing number of cases with complications following tattooing. It may be due to haphazardness in practice or contents of tattoo pigment not regulated by any laws.

Common skin reaction to tattoo includes acute inflammatory reaction, allergic contact dermatitis, photoallergic dermatitis, photoaggrevated reaction, granulomatous reaction, lichenoid reaction pseudolymhomatous reaction and neoplasm ${ }^{[1]}$. Recently a perforating granulomatous reaction ${ }^{[2]}$ and granuloma annulare-like palisading granuloma has been described $^{[3-5]}$. These tattoo reactions may be attributed to various contents such as metallic salt in tattoo pigment, organic dyes mixed to get various colour shades or its carrier solution $^{[5]}$.

The aim of the study is to highlight the common tattoo pigment responsible for reaction, various cutaneous manifestations of tattoo reaction and their correlation to histopathological findings.

\section{Materials and Methods}

During the period from July 2014 to June 2015, a total of 11patients came to out-patient department of our institute with variable complaints after undergoing tattooing.The cases ranged from age group of 16 to 32 years. All these patients after detail history taking, clinical examination and photographic records asked to undergo skin biopsy. After obtaining consent, wedge biopsy done following all universal aseptic precautions. Preferably part of tattoo showing visible skin changes choose for skin biopsy. The biopsy obtained was processed by standard formalin fixating paraffin embedding methods.

\section{Results}

In the above mentioned period, out of the 11 cases reported, reactions to tattoo were lichenoid reactions in 4 cases (Fig
1), foreign body granulomatous reactions in 3 cases (Fig 2), acute eczematous reaction in 2 cases (Fig 3), keloid-like reaction in 1 case (Fig 5) and granuloma annulare like reaction in 1 case (Fig 5). In all these cases Z-N stain for acid fast bacilli (AFB) were negative and patch test could not tried because of unavailability of real pigment for test.Histopathological examination for lichenoid reactions (Fig 1) revealed irregular acanthosis, parakeratosis and hyperkeratosis. Dermis showed dense inflammatory infiltrate of lymphocytes and black pigment. Occasional foreign body giant cells were also seen, suggesting lichenoid reaction to tattoo. The foreign body reactions (Fig 2) showed deposition of exogenous tattoo pigment in dermis with surrounding lymphocytes and multinucleated giant cells. The acute eczematous reaction (Fig 3) demonstratedfeatures of acute non- specific inflammatory reaction. Epidermis showed mild hyperkeratosis. Dermis showed moderate degree of perivascular and periadnexal lymphocytic infiltrate.The keloid like reaction (Fig 4) showed flattened epidermis with hyperkeratosis. Dermis showed fibroblast and myofibroblast with thick glassy collagen extending to epidermis. Congested blood vessels seen with mild inflammatory infiltrates.The granuloma annulare like reaction (Fig 5) revealed aggregates of lymphocytes and histiocytes with multinucleated giant cells and degenerated collagen in dermis. Macrophages containing granular brownish black tattoo pigments were also seen.

Patients with inflammatory skin reaction (lichenoid and granulomatous reaction) were treated with topical steroids with rapid improvement in lesions. Acute eczematous reaction treated with topical antibiotics. Keloid like reaction treated with intralesional triamcinolone injection. Because ofunavailability of Q- switched Nd-YAG laser, it could not be tried.

\section{Discussion}

Nowadays tattooing is quite popular among youth. With this changing trend there is also increase in cases presented with complications following undergone tattoo. There is need of increase in awareness among practitioners about these complications and also appropriately counsel there patients 


\section{International Journal of Science and Research (IJSR) \\ ISSN (Online): 2319-7064}

Index Copernicus Value (2013): 6.14 | Impact Factor (2014): 5.611

on risk of tattoo placement. Numerous tattoo complications have been described in literature.

Classification of tattoo pigment reactions-

1) Acute inflammatory response-

2) Infections reported are pyogenic infections,leprosy, syphilis, tuberculosis ${ }^{[6]}$, tetanus, verruca vulgaris ${ }^{[7,8]}$, herpes simplex and zoster, molluscumcontagiosum ${ }^{[9]}$, viral hepatitis and dermatophyteinfections ${ }^{[10]}$.

3) Chronic inflammatory reactions- Lichenoid, Granuloma (Sarcoidal $^{[11]}$,Granuloma annulare ${ }^{[12]}$, Necrobiotic Granulomatous $\left.{ }^{[13]}\right)$, Pseudolymphomatous ${ }^{[14]}$

4) Allergic reaction- Contact, Photoallergy ${ }^{[14]}$

5) Perforating reactions ${ }^{[11]}$

6) Hyperplastic- Pseudoepitheliomatous hyperplasia ${ }^{[14]}$, Keloid like reaction ${ }^{[15]}$

7) Koebners Response ${ }^{[15]}$

8) Scleroderma or morphea like ${ }^{[14]}$

9) Neoplasms- Basal cell Carcinoma ${ }^{[16]}$,melanoma, keratocanthoma, lymphoma ${ }^{[17]}$ and reticulohistiocytoma may be coincidental.

In our study lichenoid reaction found to be most common reaction pattern which was presented with erythematous and indurated plaque with scaling which is rare. Sanghaviet al ${ }^{[18]}$ also have reported cases of lichenoid reaction presented with similar findings. Granuloma annulare like reaction is one of the less common finding ${ }^{[12]}$, we found same finding in one case. Acute eczematous reaction which may be due to either contact allergic or irritant dermatitis frequently seen to red ink, we found same reaction pattern in two cases restricted to red ink which often contains mercury sulfide without involving of surrounding other colour ink. This is reflected in a literature review of 17 case reports by Abereret al. ${ }^{[19]}$ which showedthat red ink was responsible for 11 out of 26 reactionsreported.

Various tattoo pigments and their contents decide the frequency and nature of tattoo reaction. Composition of tattoo pigments is neither standardized nor regulated by any laws.

Tatoo pigments and content:

\begin{tabular}{|c|c|c|}
\hline & Inks & Contents \\
\hline 1 & Black ink & Iron oxides and various carbons \\
\hline 2 & Blue ink & Cobalt, chromium and copper salts \\
\hline 3 & Green ink & Primarily chromium and copper \\
\hline 4 & Red ink & High levels of mercury \\
\hline 5 & $\begin{array}{c}\text { Contemporary } \\
\text { red ink }\end{array}$ & $\begin{array}{c}\text { Mixtures of cadmium and sometimes iron } \\
\text { oxides }\end{array}$ \\
\hline 6 & Purple & Manganese \\
\hline
\end{tabular}

Red pigment containing especially mercury sulfide (cinnabar) is responsible for most of the lichenoid tattoo reactions, foreign body granulomatous reaction, acute eczematous reaction and psedolymphomatous reactions. While yellow tattoo pigments containing cadmium sulfide is at most risk of photo-aggravated reaction. In our study we found red pigment is most common pigment responsible for complications.

\section{Conclusion}

Our study on small number of patients highlights the spectrum of reaction to tattoo pigments ranges from mild nonspecific inflammation to severe reactions causing significant morbidity. Lichenoid reaction is most common tattoo reactions according to our study. Red dye in the tattoo pigment has been documented to elicit more reactions. Our study is subjected to several limitations due to number of patients involved. Further studies should be done to evaluate the same.

\section{References}

[1] Ortiz AE, Alster TS. Rising concern over cosmetic tattoos. DermatolSurg 2012;38:424-9.

[2] Sweeney SA, Hicks LD, Ranallo N, Iv NS, Soldano AC. Perforating granulomatous dermatitis reaction to exogenous tattoo pigment: A case report and review of the literature. Am J Dermatopathol 2011. [In press]

[3] Kluger N, Godenèche J, Vermeulen C. Granuloma annulare within the red dye of a tattoo. J Dermatol 2012;39:191-3.

[4] Bagwan IN, Walker M, Theaker JM. Granuloma annulare-like tattoo reaction. J CutanPathol 2007;34:804-5.

[5] Kluger N, Godenèche J, Vermeulen C. Granuloma annulare within the red dye of a tattoo. J Dermatol 2012;39:191-3.

[6] Alcalay J, David M, Shohat B, Sandbank M; Generalized vitiligo following Sezary syndrome. Br J Dermatol, 1987; 116(6): 851-855.

[7] Winkelmnn RK, Buechner SA, Diaz-Perez JL; PreSezary syndrome. J Am AcadDermatol, 1984; 10(6): 992-999.

[8] Venencie PY, WinkelmannRK, Puissant A, Kayle RA; Monoclonal gammopathy in Sezary syndrome. Report of three cases and review of the literature. Arch Dermatol, 1984; 120(5): 605-608.

[9] Suchin KR, Cassin M, Gottleib SL, Sood S, Cucchiara AJ, Vonderheid EC, Rook AH; Increased interleukin 5 production in eosinophilicSezary syndrome: Regulation by interferon alfa and interleukin 12. J Am AcadDermatol, 2001; 44(1): 28-32.

[10] Kim YH, Bishop K, Varghese A, Hoppe RT; Prognostic factors in erythrodermic mycosis fungoides and Sezary syndrome. Arch Dermatol, 1995; 131(9): 1003-1008.

[11] Sweeney SA, Hicks LD, Ranallo N, Snyder N, Soldano AC; Perforating granulomatous dermatitis reaction to exogenous tattoo pigment:A case report and review of the literature. Am J Dermatopathol, 2013; 35(7): 754756.

[12] SubhashKashyap, Vinay

Shankar, UdayKhopkar.Granuloma annulare-like palisading as a histological reaction to a tattoo. Indian $\mathbf{J}$ DermatolVenereolLeprol 2013;79:231-4.

[13] Wood A, Hamilton SA, Wallace WA, Biswas A; Necrobiotic granulomatous tattoo reaction : report of an unusual case showing features of both necrobiosislipodica and granuloma annulare patterns. Am J Dermatopathol, 2014; 36(8): 152-155. 


\section{International Journal of Science and Research (IJSR) \\ ISSN (Online): 2319-7064 \\ Index Copernicus Value (2013): 6.14 | Impact Factor (2014): 5.611}

[14] Ortiz AE, Alster TS; Rising concern over cosmetic tattoos. DermatolSurg, 2012; 38(3): 424-129.

[15]Gon AS, Minelli L, GarbosaMeissner MC; Keratocaanthoma in a tattoo. Dermatol Online J, 2009; 15(7): 9

[16] Sentis HJ, Willemze R, Scheffer E; Histopathologic studies in Sezary syndrome and erythrodermic mycosis fungoides: a comparison with benign forms of erythroderma. J Am AcadDermatol, 1986; 15(6): 12171226.

[17] Kamarashev J, Burg G, Kempf W, Hess Schmid M, Dummer R; Comparative analysis of histological and immunohistological features in mycosis fungoides and Sezary syndrome. J CutanPathol, 1998; 25: 407-412.

[18] Sanghavi SA, DongreAM, Khopkar US. Tattoo reactions-an epidemic on the surge: A report of 3 cases. Indian J DermatolVenereolLeprol 2013;79:231 -4.

[19] Aberer W, Snauwaert JE, Render UM. Allergic reaction to pigments and metals. In: Christa De Cuyper, editor. Dermatologic complications with body art: Tattoos, piercings and permanent makeup, 1st ed. Belgium: Springer link; 2010. p. 66-73.



Figure 1: Erythematous plaques and papules with superficial scaling were seen over the areas where red ink was present originally. Histopathology showing dense band like lichenoid infiltrate and tattoo pigment in the subepithelium with basal cell degeneration. (H\&E, x 100) 
International Journal of Science and Research (IJSR)

ISSN (Online): 2319-7064

Index Copernicus Value (2013): 6.14 | Impact Factor (2014): 5.611

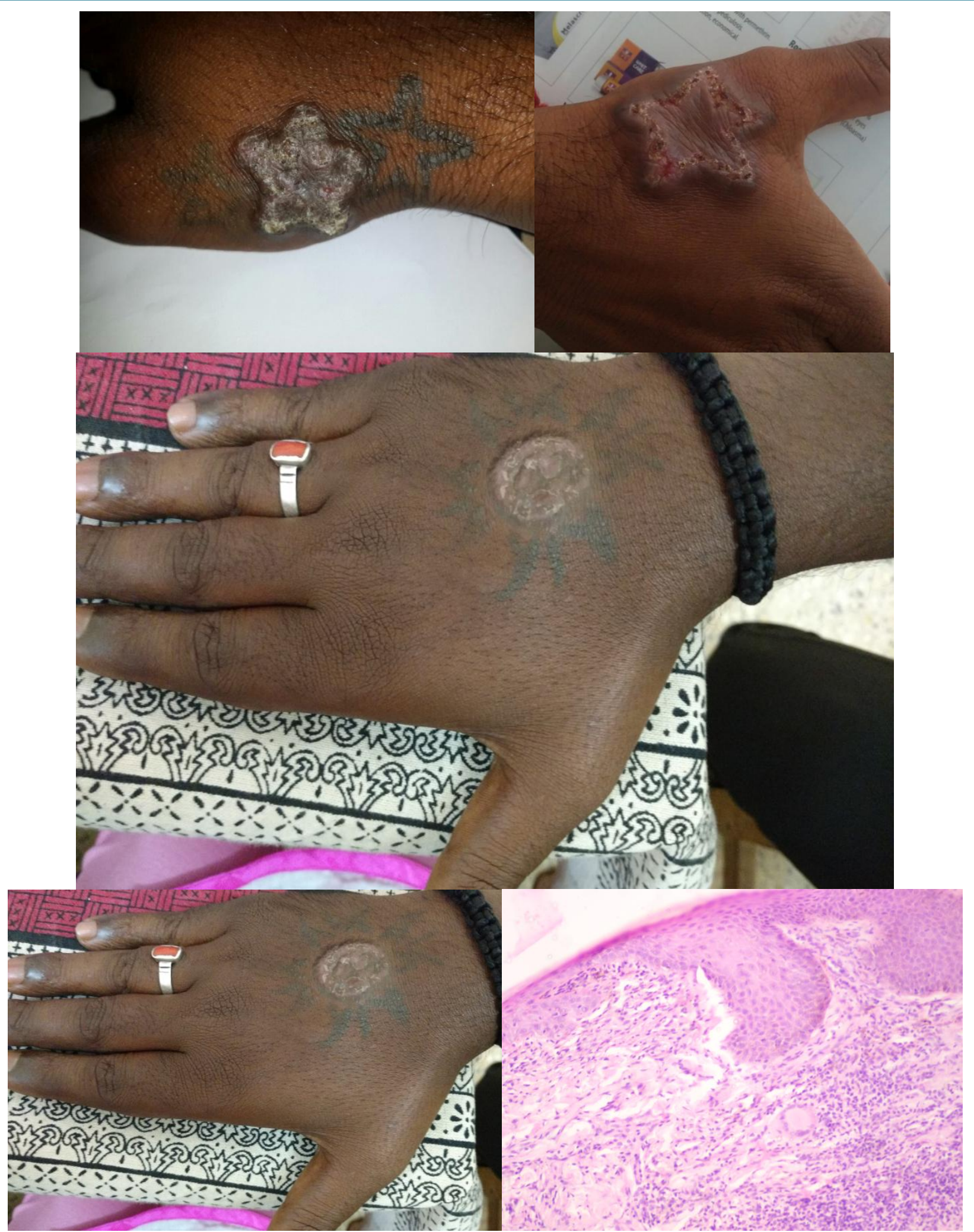

Figure 2: Erythematous indurated scaly plaques. Histopathology showed features suggestive of foreign body granuloma with deposition of exogenous tattoo pigment in dermis with surrounding lymphocytes and multinucleated giant cells. (H\&E, $\mathrm{x} 100$ )

Volume 4 Issue 12, December 2015 www.ijsr.net 


\section{International Journal of Science and Research (IJSR) \\ ISSN (Online): 2319-7064}

Index Copernicus Value (2013): 6.14 | Impact Factor (2014): 5.611

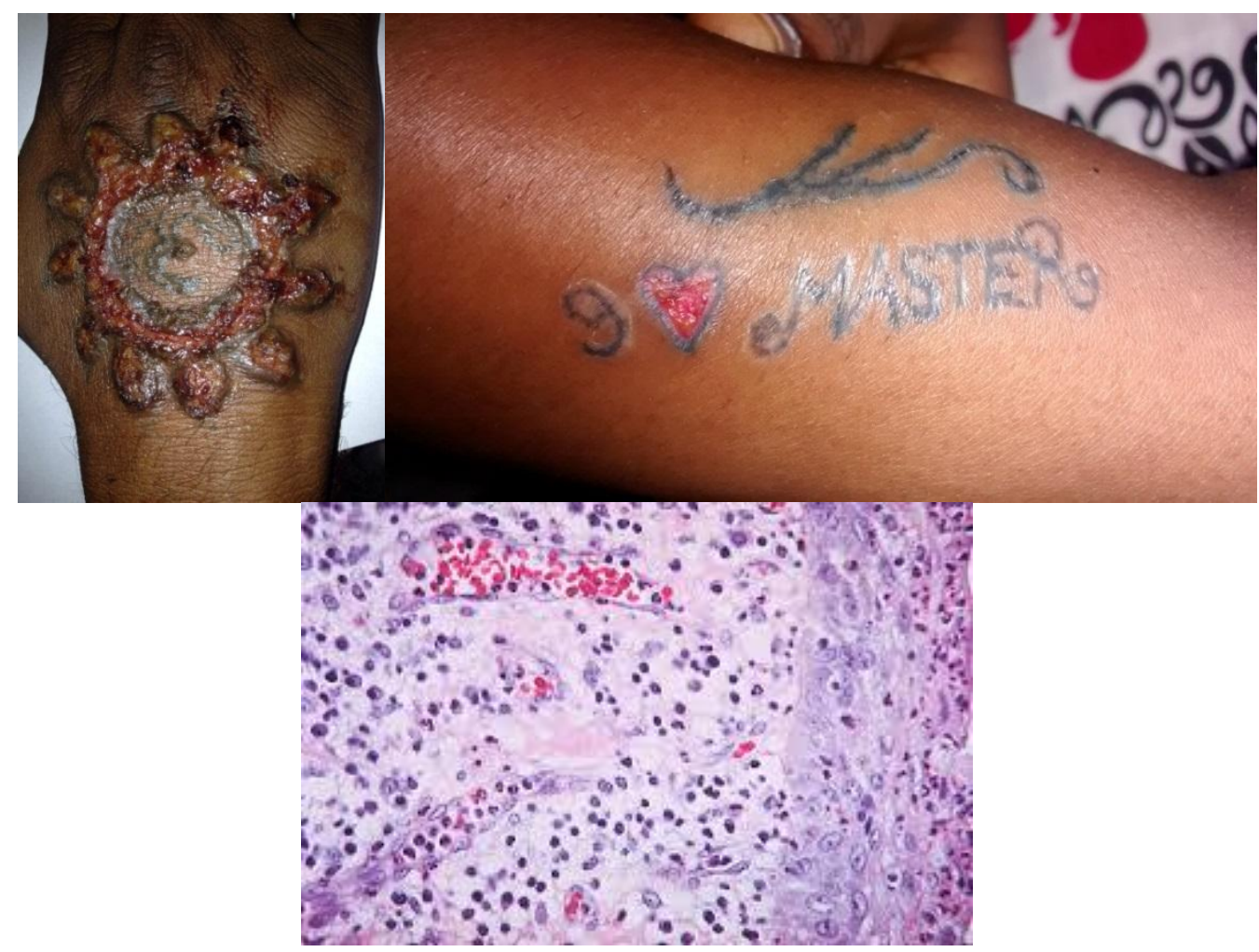

Figure 3: Crusted lesions present with erosions over red ink. Histopathology showed features of acute non- specific inflammatory reaction with moderate degree of perivascular and periadnexal lymphocytic infiltrate in dermis. (H\&E, $\mathrm{x} 100)$

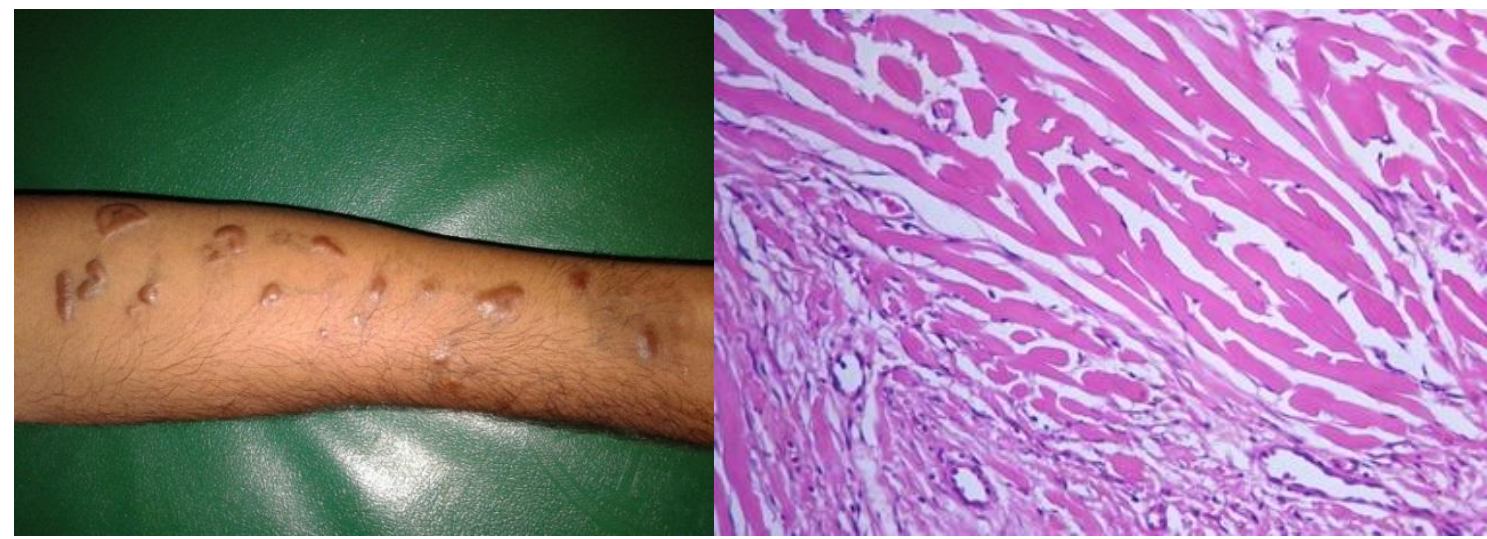

Figure 4: Multiple hyperpigmented, indurated nodules seen. On histopathology keloid like reaction showed fibroblast and myofibroblast with thick glassy collagen in dermis. Congested blood vessels seen with mild inflammatory infiltrates.(H\&E, $x$ 100)

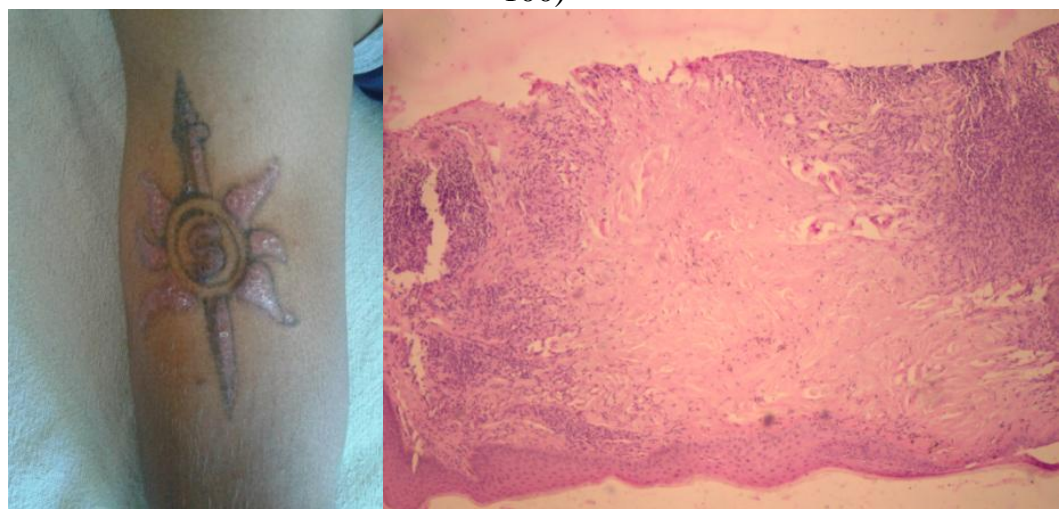

Figure 5: On examination erythematous plaque with scaling was observed over red dye tattoo. The $\mathrm{H}$ and $\mathrm{E}$ stained sections of biopsy showed granuloma annulare like tattoo reaction. Dermis was showing aggregates of lymphocytes and histiocytes with multinucleated giant cells and degenerated collagen. Macrophages containing granular brownish black tattoo pigments were also seen.(H\&E, x 100) 